\title{
On Translation Strategies of English Product Instruction From the Perspective of Skopos Theory
}

\author{
ZHAO Bin \\ Beijing Information Science and Technology University, Beijing, China
}

\begin{abstract}
With the acceleration of economic globalization, instructions, as an important attachment to a product, are of great significance. Products' instructions are information descriptions about the features, functions, ingredients, and operation of commodities. Based on the Skopos Theory, this approach was proposed in the late 1970s and early 1980s by Reiss and Vermeer. The language features and text types of instructions will be analyzed in this paper including relevant translation strategies in informative, aesthetic, and target cultural aspects to improve the translation of product instructions. In the process of the practice of translating English products' instructions, the translator should equip himself with certain responsibilities and abilities demanding by the instructions translation, which is all Skopos-oriented.
\end{abstract}

Keywords: instruction, Skopos, Functionalism, faithful, target culture

\section{Introduction}

With the rapid development of international business, industrial products sweep into our domestic market. An instruction is defined as a printed text containing a set of logical items that explains what a product is and how to use it. It is also a medium to warn the consumers about possible hazards associated with misuse and misapplication of the product.

Based on the Skopos Theory, the core theory of Functionalism, the author analyzes the language features and text types of instructions, and puts forward three translation principles and three translation methods: literal translation, free translation, and localization translation.

\section{Skopos Theory}

"Skopos" is a Greek word for "purpose", which is a term for the aim or the purpose of a translation and the translational action. The purpose of translation in the decision-making process of the translational action is more important than that of the source text, because in some cases the source text author does not write for the target revivers.

The Skopos Theory to instruction translation is purpose-oriented. As the core of the functionalist theory, the Skopos Theory consists of three rules, namely, the Skopos rule, the coherence rule, and the fidelity rule in terms of importance. Such rules enable translators free from the dilemmas of literal translation vs. free translation, and

ZHAO Bin, lecturer, Foreign Studies College, Beijing Information Science and Technology University. 
render translators the right to choose proper translation methods according to the translation purpose. Therefore, it is feasible and practical to apply the Skopos Theory to the translation of instructions, and explore instruction principles and strategies aiming to improve the translation of product instructions.

\section{Language Features and Text Types of English Instructions}

The Skopos Theory, as the prime principle of Functionalism, believes "the end justified the means" (Reiss \& Vermeer, 1984, p. 119, as cited in Munday, 2001). As for instruction writing, the purpose of the writer is to instruct the consumer how to use or operate the products easily and avoid some potential hazards correctly, which determines the contents of the instruction.

\section{Lexical Features}

\section{Accurate and Simple Vocabulary in Instructions}

Full and accurate words should be provided in product instructions. The product instructions must provide clear and complete information about the product to avoid confusion and obscurity. Since the basic function of instruction — to be easily read and followed — decides the words selection principle: accurate and simple, the instruction applies the frequent use of small words. The complicated words can only lead to difficulties in understanding.

The following verbs are often used in instructions: avoid, begin, catch, check, close, control, cut, enter, fill, get, hold, keep, press, put, reset, select, stop, turn, take, use, etc.

\section{Frequent Use of Abbreviations}

In order to express more economically, many words and phrases are used in the abbreviated form. Those abbreviations constitute one of the most striking features of instruction text (see Table 1).

Table 1

Illustrations of Frequent Use of Abbreviations

\begin{tabular}{|l|l|}
\hline Abbreviations & Full forms \\
\hline DVD & Digital Video Disk 数字视频光盘 \\
\hline HD & Hard Disk 硬盘 \\
\hline LCD & Liquid Crystal Display 液晶显示器 \\
\hline V & Volt 伏特 (电压单位) \\
\hline Batt & Battery 电池 \\
\hline ST & Stereo 立体声 \\
\hline MMS & Multimedia Messaging Service 彩信 \\
\hline 3G & 3rd Generation 第三代移动通信技术 \\
\hline
\end{tabular}

A large number of abbreviated forms appear in instruction texts, as they are familiar by consumers, so as to make the text concise, save its limited space and avoid difficulties in spelling them out in their full forms.

\section{Syntactic Features}

\section{Simplicity and Succinctness}

Simplicity and succinctness are the most distinct features of the instruction sentences. First, the words used are simple in form except those technical and scientific terms; second, instructions mainly use present tense, and 
sometimes use present continuous tense and simple future tense; third, the sentence structures are comparatively simple in regular order (see Examples 1-2).

Example (1) It is resistant to high temperature and heat. 本产品耐高温、抗热。

Example (2) The product is suitable for use in construction sites and warehouses for installation of equipment. 该机器适用于建筑工地, 仓库等地进行设备安装。

\section{Frequent Use of Imperative Sentences}

Due to the nature of instruction texts of giving command and directions about things and processes, etc., the use of imperative sentence is the most outstanding linguistic feature in the language of instructions. A well written instruction with a clear and authoritative tone immediately convinces its readers of the accuracy and the validity of the steps they have to perform, even though it may be new to them and highly complex. The imperative sentence in instruction texts often begins with a strong verb (see Examples 3-4).

Example (3) Dial 13800138000 and follow the voice instructions to recharge your China Mobile account. 本卡可用于中国移动客户充值服务，请拨13800138000，按语音提示操作。

Example (4) Do not dispose of batteries in a fire since there may be an explosion. 勿将电池投入火中，这可能引起爆炸。

\section{Text Types of Instruction}

A full version of English instruction almost contains the following three text types. Informative text type intends to provide information, representing objects, and facts. The language dimension of this kind of type is usually logical and it is content-focused. As for expressive text type, it attempts to express text sender's attitude, giving some specific kinds of moods or feelings that the text sender hopes, the language of expressive text type is usually aesthetic and it focuses on language forms. Operative text type tries to make an appeal to the text receivers, to arouse some kinds of actions that the text writer wants.

Based on the Skopos Theory and text type theory of Functionalism, translators have the duty to keep the target text accurate, concise to understand and to achieve the informative, expressive, and operative functions as its text type during the process of instruction translation.

\section{Strategies on the Translation of Instructions}

According to Skopos Theory, the translator's choice of translation strategies is always guided by the purpose of translation.

\section{To Provide Adequate Information Objectively}

Translation of products' instructions is a very important base to establish a good credibility in target country. Instructions have to be informative enough to tell consumers some information about the products objectively in accordance with the language features and text types of English instructions. It is generally believed that products' instructions should be of high information value. Successful products' instructions carry as much information as possible to provide the consumers with adequate information about characteristics and use directions of the products.

For example, all instructions of medicine contain characters, such as “Drug Name” (药品名称), 
“Pharmacological Actions” (药理作用), “Indications” (适应症), “Contraindications” (禁忌症), “Dosage and Administration” (用量及用法), “Adverse Reactions” (不良反应), and “Precautions” (注意事项).

\section{To Be Aesthetic Appropriately}

Apart from being an information providing product, instruction sometimes is also a piece of art due to its function to provide aesthetic entertainment to the audience. One major Skopos of products' instructions is to give audience aesthetic appealing and evoke their purchasing desire. In addition to imperatives or rhetorical questions, the function may also be achieved indirectly through linguistic or stylistic devices, such as superlatives, adjectives, or nouns expressing positive values, which can be frequently seen in both English and Chinese instructions (see Example 5).

Example (5) ST: Poly Clean is specially formulated to clean all dirt and stain from glass, window and other hard surfaces quickly and easily. It leaves no streak, and restores beautiful sparking shine.

TT: 保洁丽配方独特, 能迅速清除玻璃、窗户及其它硬物表面的污垢和尘迹, 方便快 捷。用后不留痕迹, 令物件光洁明亮。

This is a part of the instruction for Poly Clean which employs the popular linguistic compounds in Chinese一four-character compounds, such as “配方独特”, “迅速清除”, “不留痕迹”, and “光洁明亮”. This kind of wording can not only provide accurate information about products, but also convey a profound meaning in very concise structure with strong rhythm and rhyme.

\section{To Adapt to the Target Culture}

Language and culture are inextricably intertwined. The Skopos of products' instructions translation is to make information about products make sense or comprehensible to target consumers with different culture backgrounds. It is essential that adaptations or adjustments be made to the source text or purposeful selections of translation techniques in order to conform to linguistic, cultural, marketing, legal, and other norms in the target culture so that the translated product instructions can be well accepted by the target consumers and can perform their functions successfully in the target market (see Example 6).

Example (6) ST: CAUTION: In case of eye contact, clean your eyes with water. If swallowed, drink plenty of water and consult physician immediately.

TT: 注意事项 : 若不慎此液沾眼, 请立即用清水冲洗。如误饮本清洁剂, 请立即引用 大量清水并请医生诊治。

In the sentence, the source text consists of two imperative sentences, including three verbs. The Chinese version puts “请” in front of every verb. Cultural adaptation in the translation of products' instructions can create a sense of intimacy and make the translation accepted by the target audience more easily.

\section{Conclusions}

Due to the basic principles of Skopos Theory and the unique features of products' instructions, the translation of this genre has its own criteria and purposes. The instruction translation can be improved in three aspects-information providing, aesthetics, and culture. In the process of the practice of translating English products' instructions, the translator should equip himself with certain responsibilities and abilities demanding by the instructions translation, which is all Skopos-oriented. 


\section{References}

Goodrum, C., \& Dalrymple, H. (1990). Advertising in America: The first 200 years. New York: Harry N. Abrams. Munday, J. (2001). Introducing translation studies, theories and applications. London: London and New York.

Nida, E. A. (1993). Language, culture and translating. Shanghai: Shanghai Foreign Education Press.

Nida, E. A., \& Taber, C. (1969). The theory and practice of translation. Leiden: Brill.

Nord, C. (2001). Translating as a purposeful activity_Functionalist approaches explained. Shanghai: Shanghai Foreign Language Education Press.

PAN, H. (2004). Business English course in English-Chinese translation. Fuzhou: China Business Press.

TANG, L. L. (2005). On English translation of the product instruction. Guilin Journal of Aerospace College, 3(4), 10.

WENG, F. X. (2002). Translation practice. Zhejiang: Zhejiang University Press. 